\title{
Textualidades têxteis e novas- velhas concepções de memória na Arte Latino-americana
}

\author{
Textile textualities and new-old conceptions of \\ memory in Latin Ametican Art \\ Textualidades textiles y nuevas-antiguas concep- \\ ciones de la memoria en el Arte Latinoamericano
}

Natália Rezende Oliveira Artista e pesquisadora. Doutoranda em Artes Plásticas, Visuais e Interartes pelo PPGArtes da EBA/UFMG, bolsista CAPES/PROEX. Instituição: Universidade Federal de Minas Gerais E-mail: natalia.rzd@gmail.com ORCID: https://orcid.org/0000-0002-4751-4338

RESUMO:

Neste artigo, pretendo apresentar algumas das aproximações linguísticas, históricas e metafóricas entre os meios têxteis e a criação de narrativas, aproximações estas que serão apropriadas e ressignificadas por artistas mulheres situadas na América Latina enquanto estratégias de rememoração e reinvenção de suas próprias histórias. A partir de conceitos como a textualidade têxtil em José Sánchez-Parga, interculturalidade em Silvia Rivera Cusicanqui e tensionamentos da arte nas concepções indígenas e ocidentais, proponho uma discussão acerca da porosidade e do movimento enquanto potências textuais do tecido tal como se apresenta na arte contemporânea.

Palavras-chave: Têxteis. Memória. Narrativa.

\section{ABSTRACT:}

In this article, I intend to present some of the linguistic, historical and metaphorical approaches between the textile media and the creation of narratives, approaches that will

OLIVEIRA, Natália Rezende. Textualidades têxteis e novas-velhas concepções de memória na Arte Latinoamericana.

PÓS:Revista do Programa de Pós-graduação em Artes da EBA/UFMG. v.10, n.19: mai.2020

Disponível em < $\underline{\text { https://eba.ufmg.br/revistapos }>}$

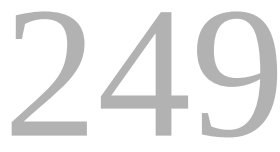


be appropriated and re-signified by women artists located in Latin America as strategies of remembrance and reinvention of their own histories. Working with concepts such as textile textuality in José Sánchez-Parga, interculturality in Silvia Rivera Cusicanqui and tensions about art in indigenous and western conceptions, I propose a discussion about porosity and movement as the textile textuality powers within contemporary art.

Keywords: Textiles. Memory. Narrative.

\section{RESUMEN:}

En este artículo, tengo la intención de presentar algunas de las aproximaciones lingüísticas, históricas y metafóricas entre los medios textiles y la creación de narrativas, aproximaciones que serán apropiadas y representadas por mujeres artistas ubicadas en América Latina como estrategias de recuerdo y reinvención de sus propias historias. Basado en conceptos como la textualidad textil en José Sánchez-Parga, la interculturalidad en Silvia Rivera Cusicanqui y las tensiones entre el arte en las concepciones indígenas y occidentales, propongo una discusión sobre la porosidad y el movimiento como potencias textuales del tejido tal como se presenta en el arte contemporáneo.

Palabras clave: Textiles. Memoria. Narrativa.

OLIVEIRA, Natália Rezende. Textualidades têxteis e novas-velhas concepções de memória na Arte Latinoamericana.

PÓS:Revista do Programa de Pós-graduação em Artes da EBA/UFMG. v.10, n.19: mai.2020 


\section{Introdução}

Há uma multiplicidade de fontes que apresentam distintas abordagens históricas acerca da inserção das materialidades e procedimentos têxteis no campo de investigação das artes visuais, deslocados de seu lugar nas artes menores ou ofícios, tal como fora compreendido pelas narrativas históricas do ocidente até meados do século XX. Em uma mirada mais recente para essas narrativas, é possível observar na atuação de artistas como Gunta Stölzl e Anni Albers, nos ateliês de tapeçaria da Bauhaus (Alemanha) dos anos 1920 e 1930, e referências posteriores como Sheila Hicks, Lenore Tawney, Louise Bourgeois, Magdalena Abakanowicz e Jean Lurçat, em meados dos anos 1970 e 1980, viradas acerca da recepção de tais linguagens. Acompanhando as transformações que o próprio campo da arte experimentava com a inserção das novas tendências do modernismo, no primeiro momento, e as experimentações de corpo e influências de movimentos sociais na produção artística e teórica da arte no segundo momento (o próprio feminismo e a retomada das materialidades têxteis associada ao engajamento político de artistas mulheres nos Estados Unidos e Europa, em meados de 1970, é um dos exemplos de abordagem em que tais materialidades são reconhecidas como provocadoras de tensionamentos à historiografia tradicional da arte).

Para as culturas ameríndias, entretanto, se a produção visual fora compreendida sob o olhar do ocidente como não sendo artística, uma vez que o conceito eurocêntrico de arte tal como forjado no Renascentismo se distinguia das relações ritualísticas e utilitárias dos objetos e ações desenvolvidas pelas diferentes culturas, contemporaneamente essa compreensão já deveria ter sido completamente dissolvida, já que parte dos pressupostos da arte contemporânea, como resultado das rupturas e criação de outras narrativas ao longo dos movimentos de vanguarda, reside justamente na expansão de sua definição a partir de uma abertura dos critérios preestabelecidos por sua história hegemônica. Porém, como observa a antropóloga Els Lagrou (LAGROU; PIMENTEL;

OLIVEIRA, Natália Rezende. Textualidades têxteis e novas-velhas concepções de memória na Arte Latinoamericana.

PÓS:Revista do Programa de Pós-graduação em Artes da EBA/UFMG. v.10, n.19: mai.2020 Disponível em < $\underline{\text { https://eba.ufmg.br/revistapos }>}$

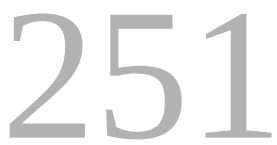


QUINTAL, 2009, p. 15), citando Lévi-Strauss, a principal diferença entre a arte "acadêmica" e a arte "primitiva", nos termos que a autora usa, ainda não fora rompida: trata-se da profunda separação entre a arte e o seu público, que seria uma das fontes da dificuldade em apreender uma produção visual e performativa ou, simplesmente, artística, das quais todos os corpos sociais fazem parte e são transformados a partir de uma relação de vida com as "coisas"."

A proposta deste artigo é conduzir uma leitura acerca das interseções entre a textualidade e as artes têxteis, tendo como ponto de partida as culturas ameríndias e andinas ressignificadas em obras de artistas latino-americanas como Cecilia Vicuña (Chile), Olga de Amaral (Colômbia), Marlene Trindade (Brasil) e Tanya Aguiñiga (México) para pensar suas estratégias na construção de narrativas de memória e no reativamento da potência textual de tais materialidades e técnicas. A partir das noções de textualidade têxtil e escrita incorporada observadas na obra de José SánchezParga, da interculturalidade ch'ixi em Silvia Rivera Cusicanqui e seus entrelaçamentos com a questão da origem, do antimonumento e da performatividade da linguagem em teóricas e teóricos do campo da antropologia e das artes, tentarei desenhar uma compreensão acerca da geração de novas-velhas concepções de memória elaboradas nas obras aqui apresentadas, que se nutrem de antigos ofícios e artifícios relativos às tradições culturais e artísticas do tecido articuladas a questões sócio-políticas contemporâneas, tangentes às vivências e contextos particulares de cada artista. Reproduzindo o movimento circular característico dos arquétipos e mitologias do tecido (DURAND, 2002, p. 321), a conexão entre temporalidades e espacialidades distintas será um dos pontos fundamentais a serem levantados a fim de elucidar a forma como proponho a compreensão dos gestos das artistas, que nos apresentarão, por fim, reflexões acerca dos movimentos do corpo e da imaginação como forças motrizes da memória inscrita no tecido.

\section{Um corpo para a memória}

Em 1804, o tear mecânico Jaquard, desenvolvido na França industrial a partir do modelo de cartões perfurados utilizados no século anterior, transformaria a produção, registro e armazenamento da informação através da viabilização dos sistemas eletrônicos que viriam a calhar, por sua vez, no

OLIVEIRA, Natália Rezende. Textualidades têxteis e novas-velhas concepções de memória na Arte Latinoamericana.

PÓS:Revista do Programa de Pós-graduação em Artes da EBA/UFMG. v.10, n.19: mai.2020 Disponível em < $\underline{\text { https://eba.ufmg.br/revistapos }>}$

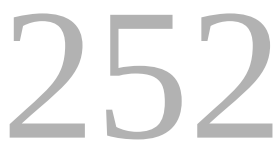


desenvolvimento da computação e, mais tarde, da internet, inserindo-nos numa rede-teia (web) que ressignificaria por completo a maneira como compreendemos, modificamos e organizamos nossa linguagem, comunicação e memória. A sofisticação desses dispositivos tem raiz direta nos fazeres manuais e parece-me preservar uma certa metodologia ritualística/simbólica do têxtil, desde sua remota origem contada na narrativa antropológica ocidental até seu desenvolvimento técnico através dos tempos, acompanhando a própria transformação das atividades humanas. No pensamento andino, localização de origem da maior parte das artistas com as quais trabalharei neste artigo, os instrumentos mnemônicos que partem de uma construção atrelada ao fio - as tapeçarias e artefatos pré-colombianos como vestimentas cerimoniais, totens, objetos de fibras e os khipus Incas - datam das origens mesmas do surgimento das comunidades, tornando a trama têxtil um dos elementos práticos e metafóricos da formação de nossa consciência histórica não apenas associada ao crescimento técnico da sociedade, mas também ao reconhecimento humano de sua potência de criar e transmitir narrativas ao longo de diferentes tempos e espaços.

A expressão "textualidade têxtil", utilizada no livro Textos Textiles en la tradición cultural andina (1995) de José Sánchez-Parga, exemplifica a relação intrínseca entre o texto e o tecido a partir do estudo de uma série de tapeçarias produzidas pela etnia Guayaki, que para além desse contexto cultural e geográfico pode ser observada também nas línguas latinas que apresentam o mesmo radical para as palavras tecer e texto: texere (CUNHA, 2007, p. 626). Segundo Sánchez-Parga, a "escrita" inaugurada nos tecidos não se restringe à função de expressar a linguagem cultural e simbólica, mas trata-se também da possibilidade de construção da própria narrativa histórica da sociedade sobre si mesma:

(...) esta escritura textil no agota el sentido de su mensaje a la función expresiva y comunicativa, sino que tiene un carácter normativo, en la medida que enuncia una idea/ideal que la sociedad reproduce de sí misma, tendiente a imprimir y codificar los comportamientos culturales (SÁNCHEZ-PARGA, 1995, p. 8). ${ }^{2}$

Numa breve introdução de como a escrita surge atrelada ao corpo, o autor fundamenta essa aproximação através da observação de marcas e cicatrizes realizadas em determinados ritos de passagem, desenvolvendo o que seria uma relação de inscrição e suporte entre ambos, sendo a pele o primeiro tecido passível de receber e carregar as grafias sociais preservando a singularidade

OLIVEIRA, Natália Rezende. Textualidades têxteis e novas-velhas concepções de memória na Arte Latinoamericana.

PÓS:Revista do Programa de Pós-graduação em Artes da EBA/UFMG. v.10, n.19: mai.2020 Disponível em < $\underline{\text { https://eba.ufmg.br/revistapos }>}$

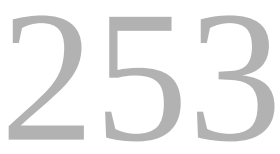


anatômica de cada membro. Sánchez-Parga prossegue em seu raciocínio afirmando que "En estos grupos sin escritura el cuerpo aparece como texto de un discurso gráfico (...)" (SÁNCHEZ-PARGA, 1995, p. 8), conferindo à escrita corporal duas características fundamentais: primeiro, a de que o poder da escrita não se constitui de um corpo autônomo, dissociado e independente da sociedade em que se realiza, como será esclarecido mais adiante, e segundo, de que a escrita corporal iguala hierarquicamente a todos os membros do grupo, "ya que todos son portadores del mismo mensaje" (SÁNCHEZ-PARGA, 1995, p. 9). A escrita atrelada ao corpo se torna, então, fator de reconhecimento e pertencimento social, atribuindo uma dimensão ética ao gesto escritural e à textualidade das fibras e peles. Ao passo que suas formas de realização se modificam, ${ }^{3}$ continua o autor, tornam-se gradativamente dissociadas do corpo para se valer de suportes como os objetos e monumentos gráficos, rompendo profundamente sua conexão com o corpo social e passando a exercer certo poder de regulamentação sobre os corpos:

La escritura sobre la sociedad deja de estar "incorporada" a esta; ya no es la escritura de la sociedad sobre si misma sino de los poderes políticos o religiosos que desde su interior se vuelven autónomos. La mayor autonomía escritural de los textos comporta su desanatomización o descorporalidad (SÁNCHEZ-PARGA, 1995, p. 9).

O autor prossegue, em seu livro, afirmando que os têxteis estariam localizados no intermédio deste processo de desenvolvimento da escrita incorporada para a escrita separada do corpo (SÁNCHEZPARGA, 1995, p. 10), uma vez que, ainda que sejam objetos externos, manteriam uma relação direta com o corpo especialmente no caso dos adornos e vestimentas, sendo elementos fundamentais na composição de determinados ritos e procedimentos da vida comum. Segundo a antropóloga Denise Y. Arnold (2019, p. 50), nos Andes contemporâneos o tecido é compreendido pelas tecelãs e tecelões como uma entidade, uma pessoa que faz parte do grupo social com um corpo e vida própria, reforçando a relação corporal da textualidade têxtil tal como apontada por Sánchez-Parga. Por outro lado, é preciso recordar que também a vida do tecido - e do texto - altera a configuração do corpo humano, como explica Els Lagrou acerca de algumas culturas indígenas da América: “(...) artefatos são como corpos e corpos são como artefatos. Na medida em que a etnologia começa a dar mais atenção ao mundo artefatual que acompanha a fabricação do corpo ameríndio, a própria noção de corpo pode ser redefinida" (LAGROU; PIMENTEL; QUINTAL, 2009, p. 39).

OLIVEIRA, Natália Rezende. Textualidades têxteis e novas-velhas concepções de memória na Arte Latinoamericana.

PÓS:Revista do Programa de Pós-graduação em Artes da EBA/UFMG. v.10, n.19: mai.2020 Disponível em < $\underline{\text { https://eba.ufmg.br/revistapos }>}$

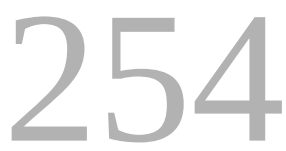


A memória em si é compreendida por Sánchez-Parga (1995, p. 9) como a subtração do esquecimento, representando a ideia de continuidade e resistência ao inevitável apagamento do tempo, “(...) um processo aberto de reinterpretação do passado, que desfaz e refaz seus nós, para que se ensaiem novamente os acontecimentos e as compreensões" (RICHARD, 2002, p. 77). Dessa forma, uma das potências dos corpos têxteis e sua textualidade seria a de carregar em sua pele, superfície e entranhas de fibras, a memória social elaborada junto do corpo de seu grupo para ser recontada continuamente através dos tempos, conforme explica:

(...) sus elaboraciones figurativas y configuraciones cromáticas, las cuales sin poseer todavía una elaboración pictográfica o ideogramática, como podría ser el caso de las "escrituras" aztecas y mayas (o la pictografía de los cuna venezolanos), no solo traducen un sistema de concepciones (ecológicas, sociológicas, religioso-rituales) sino también transmiten su memoria, en cuanto reproducción normativa de los discursos de una sócio-cultura sobre si misma (SÁNCHEZ-PARGA, 1995, p. 10).

Não só nas tapeçarias Guayaki, mas em múltiplas etnias e comunidades, os têxteis surgem como suportes de narrativas em diferentes graus de aproximação com a textualidade. Entretanto, a despeito de tal exposição ontológica do que podemos compreender como uma forma de escrita na perspectiva têxtil andina, Sánchez-Parga (1995, p. 11) nos recorda de que sua história não resume a origem da escrita em termos mais amplos, já que esta teria (se) desenvolvido (em) diferentes métodos nos diversos contextos culturais e espaço-temporais do mundo e, paralelamente, o mesmo raciocínio é aplicado na tentativa de construir uma espécie de gênese ou definição universal e imutável da prática artística desde os primórdios da vida humana. Contudo, ao fim da introdução de seu livro, o autor ressalta haver uma curiosa aproximação funcional entre a escrita da memória e a prática artística: “(...) el tejido andino con todos sus usos, funciones rituales y simbólicas, posee un carácter artístico, cuya expresividad en sociedades no gráficas adquiere un carácter comunicacional y de estereotipación de mensajes muy acusado" (SÁNCHEZ-PARGA, 1995, p. 11). É, portanto, essa relação tecida entre memória, imaginação e imagem, arte e narrativa têxtil que identificarei na observação das obras que se seguem, cada qual compreendendo a potência textual dos têxteis de distintas maneiras.

OLIVEIRA, Natália Rezende. Textualidades têxteis e novas-velhas concepções de memória na Arte Latinoamericana.

PÓS:Revista do Programa de Pós-graduação em Artes da EBA/UFMG. v.10, n.19: mai.2020 Disponível em < $\underline{\text { https://eba.ufmg.br/revistapos }>}$

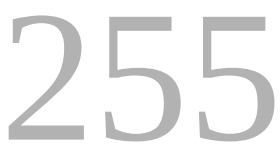




\section{Nó, tecitura, oralidade}

Na obra da artista chilena Cecilia Vicuña (1948), os elementos de narrativa relativos ao tecido no contexto andino são apropriados e ressignificados, ou seja, tornam-se atualizados pela artista em diferentes proposições. Suas obras poderiam ser organizadas em conjuntos híbridos que transitam pela arte precario, categoria criada por ela para se referir aos trabalhos que se atentam à condição processual dos materiais e à ideia de prece (observando a etimologia da palavra, que tem origem no latim precario); a recorrente menção à estrutura linear dos khipus Incas; ${ }^{4}$ as performances de poesia falada e as produções audiovisuais que correspondem à criação de documentários, obras em vídeo e registros de performances. Todas as linguagens e suportes artísticos têm em comum sua experiência com a multiplicidade das formas têxteis, que também são compreendidas pela artista numa relação de equivalência com a própria língua. Para fundamentar sua proposta, Vicuña vai buscar no quéchua ${ }^{5}$ e nas línguas dos países nos quais realiza suas performances, aproximações culturais e possibilidades de criar narrativas através da textualidade da fibra têxtil. Desfazer a palavra numa investigação etimológica, gesto comum em suas obras visuais e literárias, é para a artista como o movimento de desfiar uma linha para entrar em contato com as micro partículas que a compõem: entender sua composição é desvendar a narrativa que carrega para além dos tempos e os significados que pode provocar no momento de agora, criando desvios e passagens que resultarão em outros tipos de experiência para a criação de imagens e textualidades da memória.

Nos livros publicados no início de seu percurso artístico, tal como Saborami (Beau Geste Press, 1973), Vicuña escreve de maneira emocionada sobre a felicidade de um Chile que se desenhava sob a perspectiva socialista de Salvador Allende, sentimentos que são duramente desmantelados a partir do golpe de Estado e instauração do governo militar de Augusto Pinochet (1973). Nesse sentido, a artista, que naquele momento se encontrava na Inglaterra, opta pelo autoexílio, mantendo-se fora do Chile e no permanente trânsito que determinaria o movimento como um dos métodos fundamentais de seu processo de trabalho. Apesar da distância geográfica, suas experimentações com os khipus em Londres e nos demais países em que viveu expressavam o desejo de se conectar à cultura indígena dos Andes e aos movimentos artísticos e populares de resistência chilena à ditadura militar, tornando-se cocriadora do grupo Artists For Democracy no ano de 1974. Desde então,

OLIVEIRA, Natália Rezende. Textualidades têxteis e novas-velhas concepções de memória na Arte Latinoamericana.

PÓS:Revista do Programa de Pós-graduação em Artes da EBA/UFMG. v.10, n.19: mai.2020 Disponível em < $\underline{\text { https://eba.ufmg.br/revistapos }>}$

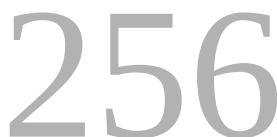


Vicuña passa a realizar obras que narram a tentativa de tecer uma memória que pudesse atravessar as frágeis películas do espaço e tempo, capazes de conectar diretamente a funcionalidade de um artefato ancestral às questões políticas do mundo contemporâneo ao abordar não só a tensa situação política do Chile e as consequências da colonização na América Latina, mas também as questões ambientais, os conflitos de território e as imigrações a nível mundial para citar algumas delas.

Esse extenso volume de memórias narradas pela artista se caracteriza, principalmente, por evocar o corpo social contra o poder institucionalizado, confluente com o movimento de reavivar a interseção entre o texto e o corpo da comunidade tal como proposto por Sanchez-Parga, elaborando um tecido mnemônico que se forma de linhas diversas, contraditórias ou não, e que estão, hoje, em um contato inevitável. A socióloga boliviana Silvia Rivera Cusicanqui utiliza a figura da tecelã como uma metáfora da interculturalidade, uma vez que a imagem do entrelace realizado na trama de um tecido descreveria os encontros e a possibilidade de estabelecer um diálogo entre as diferenças, preservando, entretanto, a singularidade de cada fio e corpo - que Cusicanqui exemplifica utilizando também a imagem do gris jaspeado, uma pedra composta de pontos brancos e pretos que, à distância, parecem formar uma única cor cinza, mas que bastaria uma aproximação de nossos olhos para percebemos que ambas as cores jamais se misturam, cada uma existe em sua unidade sendo simultaneamente a mescla formada pelo duplo contato (CUSICANQUI, 2008, p. 310).

A consciência e o trabalho sobre esse mesmo contato viria a definir o pensamento que Cusicanqui nomeia de ch'ixi, a força descolonizadora da mestiçagem que compreende esta não enquanto uma celebração do hibridismo, que, como Eduardo Viveiros de Castro aponta, não passa do processo de branqueamento das Américas (CASTRO, 2019), mas como a permanente luta subjetiva entre os pontos contrários de nossa composição, o indígena e o europeu (CUSICANQUI, 2019). A figura intercultural da tecelã, segundo Cusicanqui, representa também a consciência de que todo conhecimento adquirido passa pela experiência do e com o corpo. Fruto de uma narrativa que se constrói, portanto, de maneira autônoma e integrada à vida, o texto tecido na obra de Vicuña se refere à uma narrativa que toda a comunidade é capaz de ler, que se realiza através da ligação entre a linha e a palavra, ambas conduzindo-nos ao"centro de la memoria" (VICUÑA, 1996, p. 9).

OLIVEIRA, Natália Rezende. Textualidades têxteis e novas-velhas concepções de memória na Arte Latinoamericana.

PÓS:Revista do Programa de Pós-graduação em Artes da EBA/UFMG. v.10, n.19: mai.2020 Disponível em < $\underline{\text { https://eba.ufmg.br/revistapos }>}$

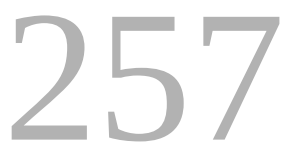




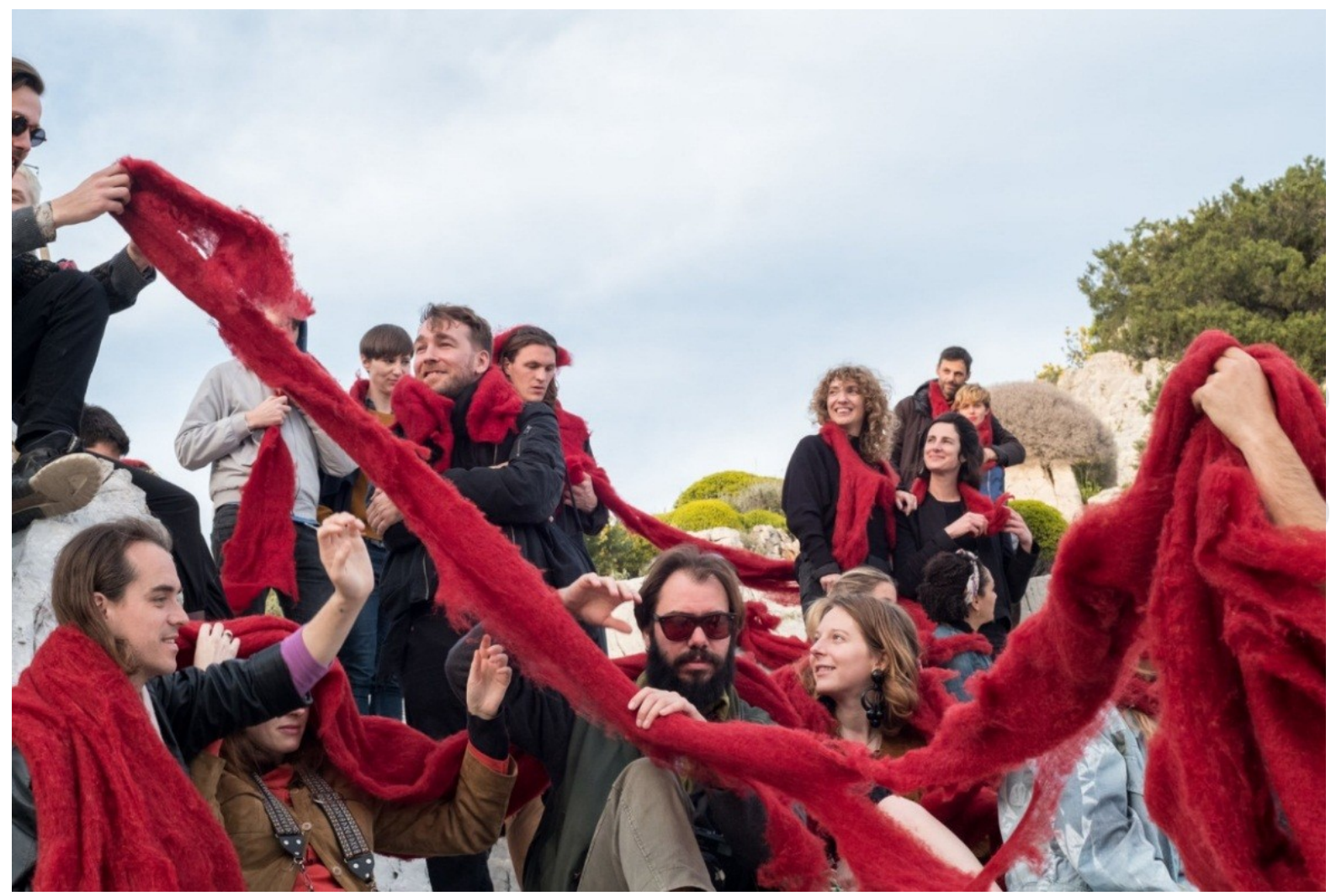

Fig. 1 - Beach Ritual. 14a Documenta de Kassel, Atenas (Grécia).

Fonte: Cecilia Vicuña, 2017. Disponível em: <http://www.ceciliavicuna.com>. Acesso em: 13 maio 2020.

Nas performances em que apresenta experiências próximas à reprodução de rituais, da prática da oralidade e do improviso, Vicuña recupera não só a dimensão intergeracional de transmissão de histórias, premissa contida no simbolismo cultural dos têxteis, mas a própria presença do corpo que transforma a linguagem em ação, que conta, dança e age, que insere na língua, na palavra, na memória, sua vitalidade e atualização, preservando a (transformação de) sua narrativa numa duração infinita do tempo. Em uma entrevista concedida ao projeto Movimientos de Tierra (2017) para relatar sobre a execução de uma de suas performances ritualísticas realizadas nesse contexto, Vicuña narra sobre seu encontro com uma imagem - e corpo - que a teria impressionado e impulsionado profundamente a desenvolver sua prática artística relativa ao entrelaçamento dos materiais têxteis às culturas originárias e à própria performance. Em uma visita escolar ao Museu de História Natural do Chile, a artista conta ter visto pela primeira vez El Niño del Cerro de El Plomo, a múmia de um menino Inca que fora encontrada no alto da Cordilheira dos Andes no ano de 1999 e teria feito parte de uma oferenda em um ritual sagrado junto de outros corpos. ${ }^{6}$ Vicuña relata que

OLIVEIRA, Natália Rezende. Textualidades têxteis e novas-velhas concepções de memória na Arte Latinoamericana.

PÓS:Revista do Programa de Pós-graduação em Artes da EBA/UFMG. v.10, n.19: mai.2020 Disponível em < https://eba.ufmg.br/revistapos $>$

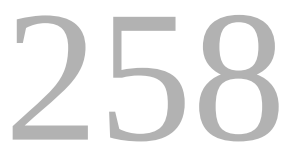


ao se colocar diante da criança no Museu, sentiu como se aquele corpo fosse o dela, e essa foi a primeira conexão que realizou com um tempo e espaço longínquo que parecia mais vivo do que o tempo e espaço que o corpo dela ocupava. Ela prossegue sua narrativa contando ter descoberto, posteriormente, que El Niño fora encontrado segurando em uma de suas mãos um pedaço de fibra vermelha (hebra roja), realizando, a partir dessa informação, uma série de obras dedicadas a reproduzir metaforicamente a oferenda da criança, que com o fio da vida prolongava simbolicamente a conexão e integração de sua comunidade às forças vitais da natureza (REZENDE, 2018, p. 133).

Em uma dessas obras, intitulada Beach Ritual (2017), a artista reuniu uma grande quantidade de lã tingida de vermelho e em estado cru para ser lançada às margens de um rio em Atenas (Grécia), na ocasião da 14a Documenta de Kassel, e convidou os espectadores da performance para fazerem parte de seu rito (fig. 1). Ao longo da execução, Vicuña conduziu as participantes através do envolvimento de seus corpos com a fibra têxtil, poesias improvisadas, sussurradas ou ditas como instruções e longos momentos de pausa e contemplação, criando uma tecitura que mesclava a língua, a lã, o gesto, a paisagem e a partilha (REZENDE, 2018, p. 149). Diante disso, compreende-se que cada participante de suas obras, sejam estas as performances colaborativas ou as instalações e intervenções no espaço, metaforicamente completa a atualização dos khipus, pois são os portadores da memória que ativam a escrita têxtil através da presença do tecido de seus corpos, formando juntos uma trama comum:

Meu Quipo é um poema no espaço, diferente de qualquer "quipo" que tenha existido. Ele é construído com a lã crua que simboliza o estado processual no qual todas as coisas nascem. Quando as pessoas caminham pela instalação, elas se tornam os nós dos quipos, os portadores da memória (VICUÑA, 2013, p. 94, tradução minha).

Curiosamente, o primeiro khipu que Vicuña teria realizado, intitulado El quipu que no recuerda nada (1966), é um objeto que não existe mais e não há nenhum registro fotográfico ou documentação que ateste sua existência em seus arquivos. A obra, que assume então um tom fictício e ao mesmo tempo verdadeiro, visto que repete justamente a narrativa do destino histórico de apagamento e esquecimento dos khipus, realiza-se apenas no testemunho proferido pela artista. Sua ausência contingente faz do desaparecimento (ou do não lembrar) uma abertura para a possibilidade da reescrita, é um convite para que reelaboremos seu significado a partir da palavra - da narrativa -

OLIVEIRA, Natália Rezende. Textualidades têxteis e novas-velhas concepções de memória na Arte Latinoamericana.

PÓS:Revista do Programa de Pós-graduação em Artes da EBA/UFMG. v.10, n.19: mai.2020 Disponível em < $\underline{\text { https://eba.ufmg.br/revistapos }>}$

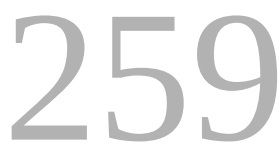


tornada potência de imaginação, imagem. Se o futuro é a imagem ausente, por excelência, da qual não podemos saber de antemão o desenho, conhecer o passado é uma forma eficiente de imaginar um mundo possível (CUSICANQUI, 2019) e, assim, as linhas desaparecidas do primeiro khipu de Vicuña representam também a narrativa dos torturados e desaparecidos políticos, dos genocídios de populações indígenas e provenientes de África, dos apagamentos sistemáticos que só podem ser vistos, ouvidos e imaginados quando suas histórias nos são contadas, ainda que pela via da fabulação inerente às conexões orgânicas e, por vezes, incontroláveis de nossa memória. A partir do acesso ao passado, abre-se a possibilidade de criar novos caminhos, portanto, é preciso que suas histórias sejam contadas, recontadas, reconstituídas desde os seus fragmentos, por menores que sejam - um fio qualquer é capaz de alterar significativamente uma paisagem, e é essa a grande descoberta e aposta da obra Vicuña.

\section{Textura, antimonumento, espacialidade}

Num movimento similar ao proposto por Cecilia Vicuña, Olga de Amaral (1932) se interessa pelos enigmas dos têxteis pré-colombianos tomando como referência, por sua vez, as tapeçarias que registram de fato alfabetos, como as Maias e Astecas, a fim de formular uma abertura para a imaginação que preserva, também, a dimensão do fascínio sobre a ilegibilidade de suas escrituras, estabelecendo, em suas obras, uma relação com a língua, escrita e oralidade diferentemente das concepções ocidentais com as quais Vicuña tenta dialogar (em operações de contraposição, complementaridade e justaposição, como visto acima). Seria preciso experimentar a textura e a espacialidade dessas tramas em questão para termos uma consciência mais aproximada da forma como uma memória pode ser concebida e transmitida, e é nesse sentido que a artista se vê estimulada a reproduzir a monumentalidade dos enigmas, das textualidades têxteis que revelariam as chaves epistemológicas necessárias para compreender os pensamentos que guiaram as grandes civilizações de Abya Yala.?

OLIVEIRA, Natália Rezende. Textualidades têxteis e novas-velhas concepções de memória na Arte Latinoamericana.

PÓS:Revista do Programa de Pós-graduação em Artes da EBA/UFMG. v.10, n.19: mai.2020 Disponível em < https://eba.ufmg.br/revistapos $>$ 
Como recurso que reforçaria a ideia da monumentalidade, em séries de esculturas como Lienzos, Alquimia e Umbra (fig. 2), produzidas entre os anos de 2014 e 2015, a artista combina as fibras utilizadas em suas tapeçarias com materiais de maior dureza, tais como gesso e folhas de ouro, associando os corpos do tecido com a rigidez e valorização de minerais e metais preciosos. AtribuindoIhes um peso e volume que modificam nosso conhecimento de sua presença enquanto material frágil e simbólico, a estratégia de Amaral representa a resiliência observada pela pesquisadora norte-americana Julia Bryan-Wilson, que se refere à extensa durabilidade material do tecido e a importância desta característica para sua sobrevivência ao longo dos tempos (BRYAN-WILSON, 2019, p. 196). Em seu livro dedicado ao estudo da tapeçaria, On Weaving (1974), Anni Albers descreve que trama e urdidura possuem um valor equivalente na estrutura de um tecido, uma vez que ambas as partes são feitas da mesma matéria e forma, com as mesmas características táteis e visuais (ALBERS, 1974, p. 63). Quando adiciona as materialidades minerais às linhas de suas tapeçarias, Amaral estaria reproduzindo tal movimento de percebê-las como partes constituintes de um único corpo:

\begin{abstract}
Suas composições tridimensionais que resultam de uma integração total entre estrutura e superfície são produzidas por um processo longo e delicado que começa pela fabricação artesanal da tapeçaria. Olga utiliza a fibra de lã, sisal, algodão, linho, e outras como vêm sendo utilizadas pelo homem há séculos. Pela tecelagem, a artista obtém fios que ela dispõe manualmente de forma a produzir uma intricada estrutura. As esculturas suspensas de Olga evocam assim o artesanato pré-colombiano e questionam também os limites entre a dominação colonial hispânica e as práticas tradicionais. Também podemos identificar no trabalho da artista a afinidade com a arte ótica e o minimalismo abstrato (BECHELANY, 2015, p. 2).
\end{abstract}

A metáfora da monumentalidade também se intensifica nos métodos e estratégias de exposição adotados pela artista: o espaço onde seu trabalho se instala recebe uma preparação de cor e luz pontuada sobre as peças, tornando o tecido uma presença que acumula tempos e realidades distintas, passível de materializar no espaço e tempo presente sua potência atemporal. A estética de tapeçarias que evidenciam a textura e a forma, as possibilidades técnicas que recuperam práticas arcaicas dos têxteis e entrelaçam experimentações contemporâneas é notável também em obras de artistas como a brasileira Marlene Trindade (1936-2018), que impulsionou as pesquisas na

OLIVEIRA, Natália Rezende. Textualidades têxteis e novas-velhas concepções de memória na Arte Latinoamericana.

PÓS:Revista do Programa de Pós-graduação em Artes da EBA/UFMG. v.10, n.19: mai.2020 Disponível em < $\underline{\text { https://eba.ufmg.br/revistapos }>}$

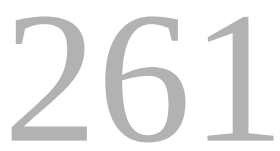


área experimental de fibras no Brasil ao inaugurar o primeiro ateliê destinado a investigações com foco no papel artesanal, na Escola de Belas Artes da Universidade Federal de Minas Gerais, em 1980 (SATURNINO, 2015, p. 54-55).

Resgatando a memória da cultura local, as narrativas de Marlene integram o corpo têxtil e a representação do espaço, aspecto também observado por Sánchez-Parga ao identificar que as representações de formas geométricas nas tapeçarias Guayaki compreendem a organização e concepção espacial desta sociedade (SÁNCHEZ-PARGA, 1995, p. 19-20), uma trama arquitextual em contraposição à noção de arquitetônico, como propõe o filósofo Henri Lefebvre (INGOLD, 2012, p. 39). No caso de Marlene, porém, os desenhos de suas tapeçarias são construídos a partir dos relevos, do vocabulário de nós e laçadas que materializam uma memória a ser lida não apenas visualmente, mas também por outros de nossos sentidos, convergindo com a organicidade tátil da memória já observada nas obras de Cecilia Vicuña.

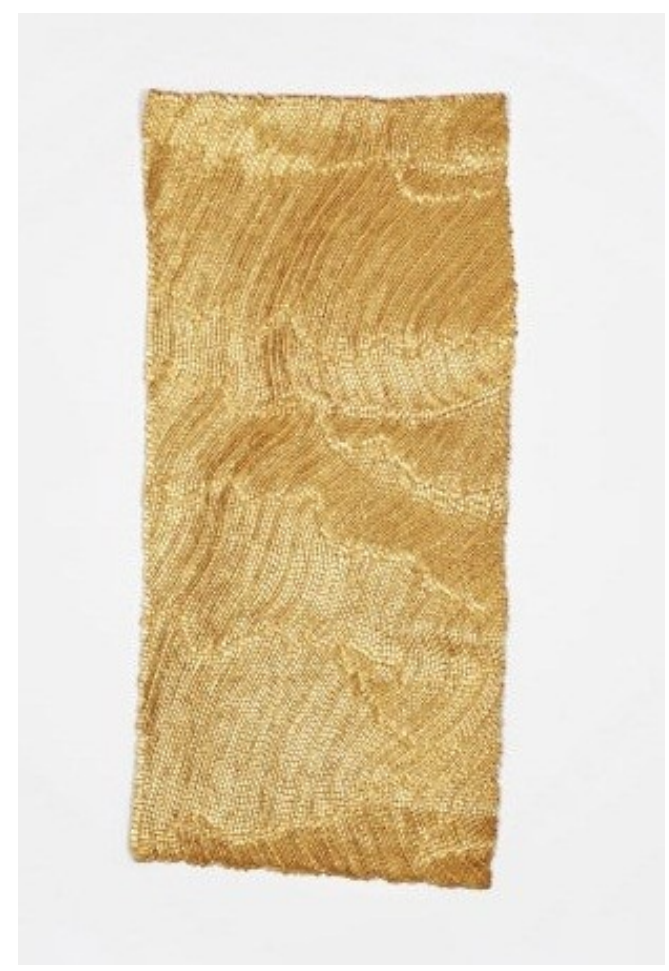

Fig. 2 - Umbra B.Fonte: Olga de Amaral, 2014-2015. Disponível em: <https://www.phillips.com/detail/olgade-amaral/NY010516/8>. Acesso em: 14 maio 2020.

OLIVEIRA, Natália Rezende. Textualidades têxteis e novas-velhas concepções de memória na Arte Latinoamericana.

PÓS:Revista do Programa de Pós-graduação em Artes da EBA/UFMG. v.10, n.19: mai.2020 Disponível em < $\underline{\text { https://eba.ufmg.br/revistapos }>}$ 

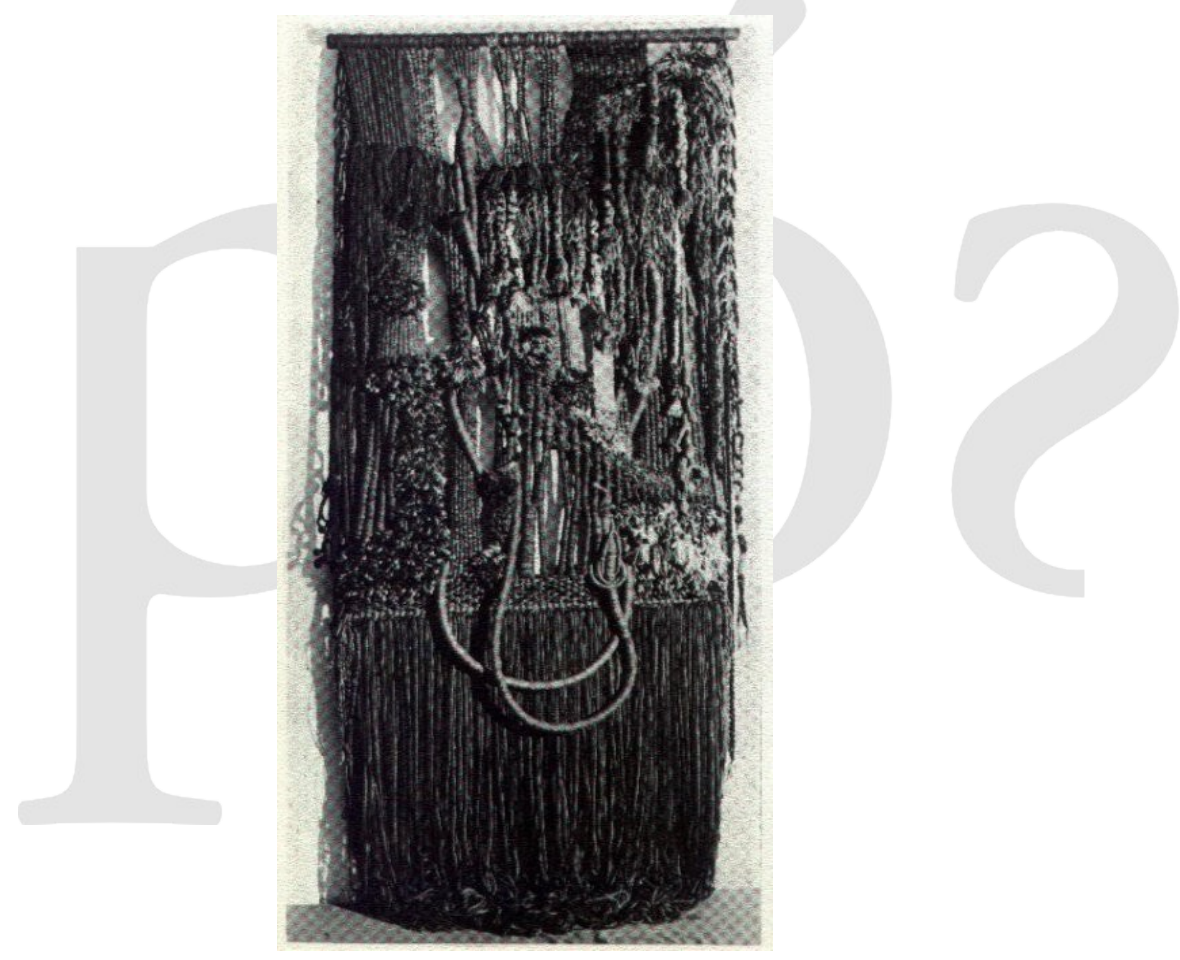

Fig. 3 - Canto do Vale do Rio Doce I.

Fonte: Marlene Trindade, 1976. Disponível em: <http://www.memoriatextil.com.br>. Acesso em: 14 maio 2020.

A tapeçaria que faz referência ao Vale do Rio Doce (fig. 3), hoje, inevitavelmente nos recorda da destruição progressiva de rios e comunidades pela ação de mineradoras, do extermínio de etnias indígenas no Brasil e dos conflitos de demarcações de terra, situações paralelas ao apagamento evocado por Olga de Amaral, no contexto da Colômbia, acerca da destruição dos têxteis, códigos culturais e populações originárias das quais os descendentes hoje permanecem marginalizados e sofrem múltiplas camadas de violência institucionalizada. As obras, portanto, configurariam muito mais uma alusão ao antimonumento e à ideia de memória ativa, ${ }^{8}$ que descrevo a seguir, do que à monumentalidade tal como a conhecemos: exercendo um poder que sustenta a soberania de uma narrativa autorizada pelo Estado em detrimento das outras. $\mathrm{O}$ termo antimonumento compreende uma categoria de trabalhos artísticos realizados a partir do final do século XX para lidar com a memória relativa aos crimes e violências do Estado, tratando-se mais precisamente do nazismo, quando relacionados ao contexto da Europa, e das ditaduras militares e processos de colonização no caso da América Latina (SELIGMANN-SILVA, 2015, p. 139). Eva Giberti (1992), por sua vez, desenvolveu o conceito de memória ativa para propor uma concepção de memória que não se reduzisse

OLIVEIRA, Natália Rezende. Textualidades têxteis e novas-velhas concepções de memória na Arte Latinoamericana.

PÓS:Revista do Programa de Pós-graduação em Artes da EBA/UFMG. v.10, n.19: mai.2020 Disponível em < $\underline{\text { https://eba.ufmg.br/revistapos }}>$

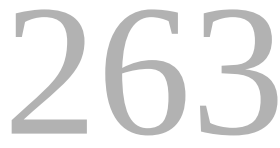


apenas à celebração da recordação, mas que fizesse uso da lembrança como uma forma de engajamento e resistência a um esquecimento que "es parte de proyectos políticos destinados a insensibilizar a la gente frente a la corrupción". Assim, as gerações futuras teriam acesso a uma narrativa do passado que alimentaria a continuidade das lutas e a garantia dos direitos dos cidadãos:

El recuerdo de los desaparecidos, de las fuerzas de seguridad saqueando, torturando, secuestrando niños, el recuerdo de la obediencia debida, del punto final y de los indultos son recuerdos que conviene enhebrar en un mismo lazo porque cuando se carece de memoria se pierde la responsabilidad personal e institucional (GIBERTI, 1992).

Na exposição "Reindigenizing the Self" (2017), a artista, designer e ativista mexicana Tanya Aguiñiga (1978), inspirada nos mitos do Popol Vuh ${ }^{9}$ e nas imagens surreais que ativam a memória e imaginação, desenha a clara mensagem - exaustivamente reivindicada por lideranças indígenas na América desde 1500 - de que podemos e precisamos aprender com os modos não ocidentais de viver a construir o mundo e nos nutrirmos dele de maneira consciente e integralizada, para garantirmos nossa sobrevivência. Movimento este de equilíbrio e conexão que, similar às propostas das artistas apresentadas neste artigo, representa-se simbolicamente no processo prático de deixar a textura conduzir a forma, conduzir o corpo que tece, deixar entrelaçar, novamente, memória ao corpo, arte à vida, observando que, aqui, tanto a memória quanto a arte são também reinventadas a partir das novas-velhas concepções e compreensões de narrativa sobre o mundo desenhadas pelas artistas.

\section{Novas-velhas conclusões: contar uma história é reinventá-la}

Estudar as aproximações entre o têxtil e a noção de escrita dentro de um recorte geopolítico como a América Latina é esbarrar em uma série de fios soltos e lacunas históricas que inevitavelmente comporão a trama textual que se deseja esboçar, quaisquer que sejam as abordagens e métodos de pesquisa utilizados. A própria materialidade têxtil é tomada pelas artistas como metáfora, material, método e símbolo, tornando impossível uma análise que desconsidere a sutileza dos trânsitos e fronteiras entre cada uma dessas características, bem como as lacunas que constituem também a

OLIVEIRA, Natália Rezende. Textualidades têxteis e novas-velhas concepções de memória na Arte Latinoamericana.

PÓS:Revista do Programa de Pós-graduação em Artes da EBA/UFMG. v.10, n.19: mai.2020 Disponível em < $\underline{\text { https://eba.ufmg.br/revistapos }>}$

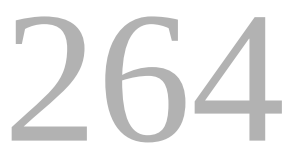


sua própria narrativa histórica. Comecei este artigo dizendo do tensionamento do conceito de arte ao se tratar das poéticas têxteis desde a elaboração de sua historiografia dentro dos padrões europeus até o entendimento das práticas em contextos tradicionais e, algumas vezes, relativos a experiências extrassensíveis, espiritualizadas. A despeito da dificuldade em desenvolver esse debate dos preconceitos e engessamentos teóricos que, a meu ver, justamente impedem o avanço dessa discussão, me parece que as artistas se apropriam de sua fragilidade mesma para potencializar os sentidos extraídos das inesgotáveis relações possíveis e fluidas entre arte, vida, corpo, texto, têxtil e memória.

Tal constatação reflete a relação ritualística e corporal dos têxteis nas sociedades pré-colombianas e as porosas fronteiras entre arte e escrita da memória, como foi discutido ao longo deste artigo, e dessa forma, os fios poderiam ser compreendidos, a guisa de uma frágil e inacabada conclusão, como a dimensão material da própria memória - sua textura, que intercala as expressões textuais e têxteis num mecanismo de leitura que é simultaneamente visual e tátil, aciona a lembrança e também se fundamenta no esquecimento. Sua decodificação não é necessariamente restrita ao entendimento de signos visuais, mas é, sobretudo, mnemônica: poderia tratar-se de um sistema de códigos que nos faz recordar, atribuindo vitalidade à memória e imaginação e reproduzindo a dimensão artesanal, e portanto, diretamente ligada aos fazeres manuais, da arte da narrativa tal como observada por Walter Benjamin em O narrador: considerações sobre a obra de Nikolai Leskov (1994). Dessa forma, não só a invenção é matéria fundadora da textualidade da memória no têxtil, como também é responsável pelo movimento circular de sua continuidade, pois como bem recorda Tim Ingold em sua obra Estar vivo: ensaios sobre movimento, conhecimento e descrição (2015), o conhecimento intergeracional não é um conteúdo estático que perdura no tempo através de sua transmissão entre os corpos. O conhecimento, em suas palavras, não é classificatório, mas narrativo (INGOLD, 2015, p. 234), e as histórias recontadas configuram-se como modos de conhecer passíveis de se desenvolverem nas performances realizadas por seus contadores - e ouvintes.

Em seu livro A farmácia de Platão (1997), Jacques Derrida sugere que a performatividade constrói o sentido da linguagem, ou seja, que a encenação conjunta entre a memória, a escrita, a língua, a literatura, a comunidade que escreve e que lê desenham uma constelação de variáveis que jamais poderia congelar o movimento da escrita, imagem ou memória. Encenar a própria identidade e

OLIVEIRA, Natália Rezende. Textualidades têxteis e novas-velhas concepções de memória na Arte Latinoamericana.

PÓS:Revista do Programa de Pós-graduação em Artes da EBA/UFMG. v.10, n.19: mai.2020 Disponível em < $\underline{\text { https://eba.ufmg.br/revistapos }>}$

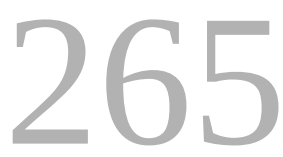


estabelecer com o passado uma relação de narrativa em constante reinvenção, atualização, é também uma das chaves conceituais propostas por Silvia Rivera Cusicanqui em seu livro Sociologia da imagem (2008), ao convocar a leitora à construção de uma etnografia de si, ou seja, de olhar para a própria memória e perceber, na História, as lacunas e faltas que estão, na verdade, preenchidas do imaginário perdido e marginal à narrativa oficial dos vencedores. A encenação da linguagem e a provocação no público de uma experiência de escrita ativa e incorporada, como visto nas narrativas apresentadas pelas artistas, são, portanto, algumas das possibilidades efetivas de transmitir não só as histórias apagadas e esquecidas, mas demonstrar que somos nós quem devemos, a partir de sua contínua lembrança e narração, sustentar sua existência. ${ }^{10}$ Os nós da memória são como trapos deixados pelo tempo, modificam nossa relação com a linguagem e tecem na imagem e na palavra a potência necessária para resistir e pensar o desafio de escrever a história ao modo como Benjamin, no século passado, nos propôs: à contrapelo (BENJAMIN, 1994, p. 225).

OLIVEIRA, Natália Rezende. Textualidades têxteis e novas-velhas concepções de memória na Arte Latinoamericana.

PÓS:Revista do Programa de Pós-graduação em Artes da EBA/UFMG. v.10, n.19: mai.2020 Disponível em < $\underline{\text { https://eba.ufmg.br/revistapos }>}$ 


\section{REFERÊNCIAS}

AGUIÑIGA, Tanya. Reindigenizing the Self. Tanya Aguiñiga. Disponível em: http://www.tanyaaguiniga.com/new-gallery-5. Acesso em: 15 ago. 2019.

ALBERS, Anni. On weaving. London: Studio Vista, 1974.

AMARAL, Olga de. Color Sombra. Catálogo: Galeria La Cometa, Bogotá D.C., fevereiro de 2015.

ARNOLD, Denise Y. Recontextualizando restos materiais: relações familiares entre alguns membros do comodato MASP Landmann e tecidos de outras coleções mundiais. In: Comodato MASP Landmann. Têxteis pré-colombianos, Márcia Acuri (Org.). São Paulo: MASP, 2019. v. 1. p.50-67

BECHELANY, Camila. Olga de Amaral, 0 Manto da Memória. São Paulo: [s.n.], 2015. Catálogo. Disponível em: <https://www.olgadeamaral.com/files/SP-Arte\%202015-BR.pdf>. Acesso em: 16 ago. 2018.

BENJAMIN, Walter. O Narrador: considerações sobre a obra de Nikolai Leskov. In: Magia e técnica, arte e política: ensaios sobre literatura e história da cultura. São Paulo: Brasiliense, 1994. p. 197-221.

BENJAMIN, Walter. Sobre o conceito da História. In: Magia e técnica, arte e política: ensaios sobre literatura e história da cultura. São Paulo: Brasiliense, 1994. p. 222-234.

BRYAN-WILSON, Julia. Feminismos, tecidos e resiliência. In: . Histórias das mulheres, histórias feministas: catálogo. São Paulo: MASP, 2019. p.195-205.

CASTRO, Eduardo Viveiros de. Estamos assistindo a uma ofensiva final contra os povos indígenas., El País, 12 out. 2019. Disponível em: https://brasil.elpais.com/brasil/2019/10/11/politica/1570796332_223092.html. Acesso em 13 out. 2019.

CUNHA, Antônio Geraldo da. Dicionário etimológico da língua portuguesa. 3. ed. Rio de Janeiro: Lexikon, 2007.

CUSICANQUI, Silvia Rivera. Tenemos que producir pensamiento a partir de lo cotidiano. El Salto. Disponível em: https://www.elsaltodiario.com/feminismo-poscolonial/silvia-rivera-cusicanquiproducir-pensamiento-cotidiano-pensamiento-indigena. Acesso em: 12 out. 2019.

CUSICANQUI, Silvia Rivera. Sociología de la imagen. Bolívia: Tinta Limón, 2008.

OLIVEIRA, Natália Rezende. Textualidades têxteis e novas-velhas concepções de memória na Arte Latinoamericana.

PÓS:Revista do Programa de Pós-graduação em Artes da EBA/UFMG. v.10, n.19: mai.2020 Disponível em < $\underline{\text { https://eba.ufmg.br/revistapos }>}$

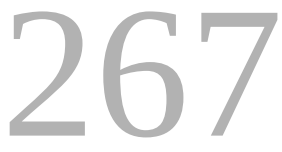


DERRIDA, Jacques. A farmácia de Platão. 2. ed. São Paulo: lluminuras, 1997.

DURAND, Gilbert. As estruturas antropológicas do imaginário: introdução a arquetipologia geral. 3. ed. São Paulo: Martins Fontes, 2002.

GIBERTI, Eva. Memoria Activa. Publicado em Página 12, dezembro de 1992. Disponível em: http://spot.net.ar/evagiberti/artículos. Acesso em 8 jul. 2019.

INGOLD, Tim. Estar vivo: ensaios sobre movimento, conhecimento e descrição. Petrópolis: Vozes, 2015.

INGOLD, Tim. Lines: A Brief History. Nova lorque: Routledge. 2007.

INGOLD, Tim. Trazendo as coisas de volta à vida: emaranhados criativos num mundo de materiais. Horiz. antropol., Porto Alegre, v. 18, n. 37, p. 25-44, jun. 2012.

LAGROU, Els.; PIMENTEL, Lucia Gouvêa; QUINTAL, William Resende. Arte indígena no Brasil: agência, alteridade e relação. Belo Horizonte: C/Arte, 2009.

REZENDE, Natália. Linhas vitais: narrativas femininas na América Latina. 2018. 204 f. Dissertação (Mestrado) - Escola de Belas Artes, Universidade Federal de Minas Gerais, Belo Horizonte, 2018.

SÁNCHEZ-PARGA, José. Textos Textiles en la tradición cultural andina. Equador: IADAP, 1995.

SATURNINO, Joice. Espaço de fazer saberes: um estudo das interfaces da arte e do conhecimento popular. 2015. 194 f. Tese (Doutorado) - Escola de Belas Artes, Universidade Federal de Minas Gerais, 2015.

SELIGMANN-SILVA, Marcio. Leila Danziger e Eugenia Bekeris: um díptico sobre a nova arte da memória. Lua Nova, São Paulo, n. 96, p. 117-147, dez. 2015.

TAYLOR, Diana; REIS, Eliana Lourenço de Lima. 0 arquivo e o repertório: performance e memória cultural nas Américas. Belo Horizonte: Editora UFMG, 2013.

VICUÑA, Cecilia. Quipus Austral. In: Les immémoriales. França, 02/03/2013 a 23/06/2013. Catálogo virtual, 2013.

VICUÑA, Cecilia. Saborami. Inglaterra: Beau Geste Press, 1973.

VICUÑA, Cecilia; ALCALÁ, Rosa. Palabra e hilo / Word and thread. Edinburgh: Morning Star Publications, 1996.

OLIVEIRA, Natália Rezende. Textualidades têxteis e novas-velhas concepções de memória na Arte Latinoamericana.

PÓS:Revista do Programa de Pós-graduação em Artes da EBA/UFMG. v.10, n.19: mai.2020

Disponível em < $\underline{\text { https://eba.ufmg.br/revistapos }>}$ 


\section{NOTAS}

1 Uso aqui o termo coisas, em aspas, tomando como referência o pensamento do antropólogo inglês Tim Ingold. Para Ingold, diferente do "objeto", as "coisas" compreenderiam uma trajetória de vida própria, seriam porosas e, por isso, atravessadas pelos fluxos vitais irradiados pela vida e o ambiente em que estão inseridas. Nesse sentido, o autor provoca reflexões e questionamentos acerca do conceito de agência estruturado por Alfred Gell, na qual o objeto é entendido como índice e é indexado a um agente. Ingold conduz sua reflexão fazendo uso de exemplos do campo artístico: “Um trabalho de arte, insisto, não é um objeto mas uma coisa e, como argumentou Klee, o papel do artista não é reproduzir uma ideia pré-concebida, nova ou não, mas juntar-se a e seguir forças e fluxos dos materiais que dão forma ao trabalho. (...) O (ou a) artista - assim como o artesão - é um itinerante, e seu trabalho comunga com a trajetória de sua vida" (INGOLD, 2012, p. 38).

2 Optei pela não tradução de citações originalmente escritas em espanhol para preservar a tonalidade e ritmo da língua materna da maior parte das artistas apresentadas. As citações traduzidas possuem esta indicação em suas respectivas referências e são de minha responsabilidade.

3 Em seu livro O arquivo e o repertório: performance e memória cultural nas Américas (2013), Diana Taylor elabora a diferença entre o arquivo, na concepção ocidental e eurocêntrica, e o repertório, que compreende um conjunto mais amplo de configurações da memória, reunindo a performatividade (seus gestos, falas e incorporações) à escrita. Os processos de "transformação" da escrita ao qual Sánchez-Parga se refere, portanto, está diretamente ligado à censura e repressão dos colonizadores aos códices e modos de elaboração de seu conhecimento, considerados inferiores à cultura escrita dos países dominantes.

4 Artefatos têxteis utilizados como um sistema de comunicação pelos povos Incas que foram, em sua maioria, queimados durante a colonização espanhola. Segundo a descrição de Tim Ingold: “The most celebrated example of a notational device that consists entirely of threads is of course the Inka khipu. The khipu comprises a plied cord to which secondary cords are attached with knots. Further, tertiary cords may be knotted to secondary ones, fourth-order to tertiary, fifth-order to fourth, and so on. Scholars still argue about the function of the khipu, whether it served to prompt the memory or to record information, and - if the latter - whether that information was merely numerical or involved elements of narrative. It seems beyond doubt, however, that almost every element of its construction carried meanings of one sort or another, including the types of knots and their placement on the cords, the ways the cords are plied, and the colour combinations used" (INGOLD, 2007, p. 67-68).

5 Idioma de origem indígena falado nos países: Argentina, Bolívia, Chile, Colômbia, Equador e Peru, sendo reconhecido como língua oficial destes três últimos.

6 Conforme: https://www.youtube.com/watch?v=2epc87AmF1c. Acesso em: 16 fev. 2020.

7 Nome dado ao continente americano pelos seus habitantes antes da invasão europeia, conforme menciona Silvia Rivera Cusicanqui. Disponível em: $<$ https://www.elsaltodiario.com/feminismo-poscolonial/silvia-rivera-cusicanqui-producir-pensamientocotidiano-pensamiento-indigena>. Acesso em: 2 out. 2019.

8 Neste artigo, como pode ser observado, reservo-me a uma apresentação pontual das noções de antimonumento e memória ativa, bem como de memória, narrativa e identidade, sem a pretensão de criar uma genealogia dos referidos conceitos. Trata-se, em verdade, de um estudo de caso com o objetivo de discutir muito mais os métodos de realização das narrativas do que de um revisionismo de suas definições.

9 Também conhecido como "Livro da comunidade", é um registro que documenta a cultura Maia, narrando desde os mitos de criação do mundo até a organização social deste povo. Acredita-se ter sido escrito no século XVI. Disponível em: <https://www.infoescola.com/historia/popol-vuh/>. Acesso em: 11 out. 2019. 
NOTAS

10 Sobre este assunto, Diana Taylor observa de forma providencial: "As performances incorporadas têm sempre um papel central na conservação da memória e na consolidação de identidades em sociedades letradas, semiletradas e digitais. Nem todo mundo chega à 'cultura' ou à modernidade por meio da 'escrita'" (TAYLOR, 2013. p. 21). 